\title{
Association study of TP53 polymorphisms with lung cancer in a Korean population
}

\author{
Hae-Yun Jung $\cdot$ Young Mi Whang $\cdot$ Jae Sook Sung $\cdot$ Hyoung Doo Shin · \\ Byung Lae Park · Jun Suk Kim · Sang Won Shin · Hee Yun Seo · \\ Jae Hong Seo $\cdot$ Yeul Hong Kim
}

Received: 13 November 2007 / Accepted: 24 February 2008/Published online: 25 March 2008

(C) The Japan Society of Human Genetics and Springer 2008

\begin{abstract}
The tumor suppressor gene, TP53, is located on chromosome 17p13.1 and is critical for DNA repair, cellcycle control, and apoptosis. TP53 also plays a crucial function in the tumorigenesis of lung cancer. Inactivation of $T P 53$ via genetic alterations such as missense mutations is often associated with lung cancer. In this study, potential association of TP53 polymorphisms with the risk of lung cancer was examined in a Korean population. A total of 299 Korean lung cancer patients and 296 control subjects were recruited into this study. Direct DNA sequencing and
\end{abstract}

This work was supported by a grant from the Korea Health 21 R\&D Project, Ministry of Health \& Welfare, Republic of Korea (A010250), and intramural grants from the Korea National Institute of Health, Korea Center for Disease Control, Republic of Korea.

Electronic supplementary material The online version of this article (doi:10.1007/s10038-008-0278-y) contains supplementary material, which is available to authorized users.

H.-Y. Jung · Y. M. Whang · J. S. Sung ·

H. D. Shin · B. L. Park · Y. H. Kim ( $\square)$

Department of Internal Medicine and Brain Korea 21 Project for Biomedical Science, Genomic Research Center for Lung and Breast/Ovarian Cancers, Korea University Medical College, 126-1, Anam-dong 5Ga, Sungbuk-Gu,

Seoul 136-705, South Korea

e-mail: yhk0215@korea.ac.kr

\section{J. S. Kim · S. W. Shin $\cdot$ H. Y. Seo · J. H. Seo}

Department of Internal Medicine and Brain Korea 21 Project for Biomedical Science, Korea University Medical College, 126-1, Anam-dong 5Ga, Sungbuk-Gu,

Seoul 136-705, South Korea

H. D. Shin · B. L. Park

Department of Genetic Epidemiology, SNP Genetics, Inc, Rm 1407, 14th floor, Complex B, WooLim Lion's Valley, Gasan-Dong, Geumcheon-Gu, Seoul 371-28, South Korea
TaqMan analysis were employed, and logistic regression analyses were conducted to characterize the association between TP53 polymorphisms and lung cancer risk. Through direct sequencing in 24 Korean individuals, 13 sequence variants were identified, and five of these polymorphisms were selected for a larger-scale genotyping $(n=595)$. Statistical analyses revealed that polymorphisms and haplotypes in the TP53 gene, including Arg72Pro, were not significantly associated with lung cancer in a Korean population.

Keywords Tumor protein p53 (TP53) .

Korean population - Haplotypes - Lung cancer .

Single nucleotide polymorphisms

\section{Introduction}

Lung cancer is one of the most common cancers and has the highest mortality rate among all cancers in Korea (Shin et al. 2005). It is a multicellular and multistage process (Hazelton et al. 2005) that involves a number of genetic changes in oncogenes and tumor suppressor genes (Sanchez-Cespedes 2003; Toloza et al. 2006). Tumor suppressor genes such as FHIT and PTEN are frequently inactivated in lung cancer by genetic alterations, including chromosomal deletions and mutations (Sozzi et al. 1998; Yokomizo et al. 1998). In particular, TP53 (OMIM no. 191170) is considered to be the most commonly inactivated gene by genetic alteration in a large proportion of lung cancer (Hollstein et al. 1991). As a typical tumor suppressor gene, TP53, located on chromosome 17p13.1, is critical for DNA repair, cell-cycle control, and apoptosis (Fuster et al. 2007), and its gene alterations have frequently been found in most human cancers (Hainaut and Hollstein 2000; Zambetti 2007). In particular, TP53 mutation is 
present in more than $90 \%$ of small-cell lung cancers (SCLC) and more than $50 \%$ of non-small-cell lung cancers (NSCLC) (Wistuba et al. 2001). Inactivation of TP53 in lung cancers leads to its loss of function as a transcription factor (Soussi 2007). Recently, much research has focused on the possible association between polymorphisms of TP53 gene-related lung cancer susceptibility, and the most extensively studied single nucleotide polymorphism (SNP) is a $\mathrm{G} / \mathrm{C}$ variation at the second position of codon 72 in exon 4, leading to Arg72 or Pro72 protein (Petitjean et al. 2007). A few studies showed that codon 72 polymorphisms in the TP53 gene are significantly associated with an increased lung cancer risk (Nadji et al. 2007; Popanda et al. 2007). On the other hand, no association between this polymorphisms and lung cancer development has been reported (Khadang et al. 2007; Rajaraman et al. 2007). Although numerous studies have analyzed the impact of codon 72 polymorphisms in the TP53 on cancer risk, these results remain largely contradictory, and no clear consensus has been reached. In this study, we attempted to characterize the association between these TP53 polymorphisms and the risk of lung cancer development in a Korean population by using genotype and haplotype analysis. Our finding indicated that TP53 polymorphisms and haplotypes, including Arg72Pro, are not significantly associated with lung cancer risk in a Korean population.

\section{Materials and methods}

\section{Study subjects}

This case-control study included 299 lung cancer patients and 296 healthy controls. The clinical characteristics of these subjects are summarized in Table 1. The eligible cases included all patients diagnosed with primary lung cancer at the Korea University Medical Center in Korea from October 2001 to April 2004. Lung cancer patients were recruited from the patient pool at the Genomic Research Center for Lung and Breast/Ovarian Cancers, and the control subjects were randomly selected from a pool of healthy volunteers who had previously visited the Cardiovascular Genome Center. Control subjects were selected from volunteers who had been screened with routine physical examination, past history, and laboratory tests, including cancer screening and diagnosis. Although specific cancer diagnostic examinations were not performed in these volunteers, chest radiograph, blood examination, and urinalysis were taken to exclude concomitant overt diseases. A detailed questionnaire, including diet, smoking status, drinking status, lifestyle, and medical history, was completed by each patient and control subject with the help of a trained interviewer. As for smoking status, anyone
Table 1 Demographic characteristics among lung cancer cases and controls

\begin{tabular}{lccc}
\hline & Control & Case & $P$ value \\
\hline Number of subjects & 296 & 299 & \\
Age (years, & $51.8 \pm 13.2$ & $62.3 \pm 10.3$ & $<0.0001$ \\
$\quad$ mean \pm standard & & & \\
$\quad$ deviation) & & & \\
Gender & & 219 & $<0.0001$ \\
Male & 283 & 80 & \\
Female & 16 & & 0.009 \\
Smoking status & & 76 & \\
Never & 90 & 204 & \\
Current & 204 & 19 & \\
Unknown & 5 & & \\
\hline
\end{tabular}

who reported smoking at least once a day was considered to be a smoker for the purpose of this study. Study subjects were approved by the Institutional Review Board of the Korea University Medical Center.

\section{Sequence analysis}

We sequenced all exons and their boundaries, including the promoter region, of the TP53 gene in 24 Korean DNA samples, using the ABI Prism 3700 DNA analyzer (Applied Biosystems, Foster City, CA, USA). All primer sets for amplification and sequence analysis were designed on the basis of GenBank sequences [Electronic supplementary material (ESM), Table 1]. The primer of the related information can be accessed at our Web site (http://www.snp-genetics.com/user/additional_list.asp).

\section{Genotyping with fluorescence polarization detection}

To genotype the polymorphic sites, all amplifying primers and probes were designed for the TaqMan system (ESM Table 2). Primer Express (Applied Biosystems) was used to design both the polymerase chain reaction (PCR) primers and the minor groove binder (MGB) TaqMan probes. One allelic probe was labeled with the FAM dye and the other with the fluorescent VIC dye. PCRs were conducted using TaqMan Universal Master Mix without UNG (Applied Biosystems) at $900 \mathrm{nM}$ PCR primer concentrations and $200 \mathrm{nM}$ TaqMan MGB-probe concentrations. The reactions were carried out in a 384-well format with a total reaction volume of $5 \mu \mathrm{l}$ using $20 \mathrm{ng}$ of genomic DNA. The plates were then placed in a thermal cycler (PE 9700, Applied Biosystems) and heated at $50^{\circ} \mathrm{C}$ for 2 min and $95^{\circ} \mathrm{C}$ for $10 \mathrm{~min}$ followed by 40 cycles of $95^{\circ} \mathrm{C}$ for $15 \mathrm{~s}$ and $60^{\circ} \mathrm{C}$ for $1 \mathrm{~min}$. The TaqMan assay plates were transferred to a Prism 7900HT instrument (Applied Biosystems) in which the fluorescence intensity in each well of the plate was read. 
Fluorescence data files from each plate were analyzed using automated software (SDS 2.1).

\section{Statistical analysis}

The $\chi 2$ tests were used to determine whether individual variants were in equilibrium at each locus in the population (Hardy-Weinberg equilibrium). Logistic regressions were used for calculating $P$ values controlling for age, gender, and smoking status as covariates. $P$ values and odds ratios (ORs) were obtained using logistic regression. Heterozygosity for each locus with allele frequencies $p$ and $q$ $(q=1-p)$ was derived using $H=1-p 2-q 2=2 p(1-p)$. We examined widely used measures of linkage disequilibrium (LD) between all pairs of biallelic loci; Lewontin's $D^{\prime}\left(\left|D^{\prime}\right|\right)$ (Hedrick 1987) and $r^{2}$. Haplotypes and their frequencies were inferred using the algorithm developed by Stephens et al. (2001). Logistic regression analysis was used to calculate ORs, 95\% confidential intervals (CIs), and corresponding $P$ values after controlling for age, gender, and smoking status as covariates. Genotypes were given 0,1 , and 2 as codes in the additive model; 0,1 , and 1 in the dominant model; or 0,0 , and 1 in the recessive model, respectively. In the additive model, OR was expressed per number of rare alleles.

The effective number of independent marker loci in TP53 was calculated to correct for multiple testing using the software SNPSpD (http://genepi.qimr.edu.au/general/ daleN/SNPSpD/), which is based on the spectral decomposition $(\mathrm{SpD})$ of matrices of pair-wise LD between SNPs
(Nyholt 2004). The resulting number of independent marker loci was applied to correct for multiple testing. Statistical powers were calculated using Statistical Power Calculator (http://www.dssresearch.com/toolkit/spcalc/ power_p2.asp).

\section{Results}

By direct DNA sequencing in 24 individuals, we identified 13 genetic variants with exons and flanking regions of TP53, including the promoter regions. Among 13 polymorphisms, five of the identified polymorphisms, including $-12256 G>C,-11917 G>A,-11849 C>T,+441 G>C$, and $+2486 C>T$, were selected for larger-scale genotyping ( $n=595$ ) on the basis of locations, frequency (over 7.5\%), LD, and haplotype tagging status (Table 2; Fig. 1). Genotype frequencies for cases and controls were in HardyWeinberg equilibrium. LD coefficients $\left(\left|D^{\prime}\right|\right)$ and $r^{2}$ among polymorphisms were also calculated (Fig. 1). All five SNPs were used for haplotype construction. Allelic frequencies of each polymorphism and haplotype were compared between patients and controls using logistic regression models (Table 3). Logistic regression analyses revealed that haplotype $3(-12256 G,-11917 G,-11849 C,+441 C$, and $+2486 C$ ) of TP53 showed marginal association with lung cancer risk in overall, male gender, and smoker groups; however, the association was lost after correction using SNPSpD. Other polymorphisms showed no association in overall analysis and all subgroup analyses. In the

Table 2 Frequencies of TP53 polymorphisms in a Korean population

\begin{tabular}{|c|c|c|c|c|c|c|c|}
\hline \multirow[t]{2}{*}{ Loci } & \multirow[t]{2}{*}{ Position } & \multirow{2}{*}{$\begin{array}{l}\text { Amino acid } \\
\text { change }\end{array}$} & \multirow[t]{2}{*}{ rs no. } & \multirow[t]{2}{*}{ Allele frequency } & \multirow[t]{2}{*}{ Heterozygosity } & \multicolumn{2}{|c|}{ Hardy-Weinberg equilibrium ${ }^{\mathrm{a}}$} \\
\hline & & & & & & Case & Control \\
\hline$-12648 \mathrm{G}>\mathrm{A}$ & Promoter & - & rs2287498 & 0.208 & 0.330 & & 0.999 \\
\hline$-12570 \mathrm{G}>\mathrm{A}$ & Promoter & - & Novel & 0.042 & 0.080 & & 0.978 \\
\hline$-12256 \mathrm{G}>\mathrm{C}$ & Promoter & - & rs2287499 & 0.232 & 0.356 & 0.864 & 0.994 \\
\hline$-11917 G>A$ & Promoter & - & Novel & 0.015 & $\mathbf{0 . 0 3 0}$ & 0.985 & 0.939 \\
\hline$-11849 \mathrm{C}>\mathrm{T}$ & Promoter & - & rs17806770 & 0.047 & 0.090 & 0.987 & 0.743 \\
\hline$+88 \mathrm{~T}>\mathrm{C}$ & Intron & - & Novel & 0.022 & 0.043 & & 0.994 \\
\hline$+112 \mathrm{G}>\mathrm{C}$ & Intron & - & rs1642785 & 0.326 & 0.440 & & 0.914 \\
\hline$+294 \mathrm{C}>\mathrm{A}$ & Intron & - & Novel & 0.065 & 0.122 & & 0.946 \\
\hline$+441 G>C$ & Exon 4 & Arg72Pro & rs1042522 & 0.368 & 0.465 & 0.805 & 0.994 \\
\hline$+1630 \mathrm{C}>\mathrm{T}$ & Exon 5 & Ala189Val & Novel & 0.021 & 0.041 & & 0.995 \\
\hline$+2486 \mathrm{C}>\mathrm{T}$ & Intron 7 & - & rs12947788 & 0.270 & 0.394 & 0.643 & 1.000 \\
\hline$+2506 \mathrm{~T}>\mathrm{G}$ & Intron & - & rs 12951053 & 0.261 & 0.386 & & 0.895 \\
\hline$+7599 \mathrm{C}>\mathrm{A}$ & $3^{\prime}$ UTR & - & novel & 0.063 & 0.117 & & 0.948 \\
\hline
\end{tabular}

Bold data indicates single nucleotide polymorphisms genotyped in a larger population $(n=595)$; nonbold data based on the sequencing data $(n=24)$

UTR untranslated region

a $P$ values of deviation from lung cancer and normal subjects 


\section{A. Map of TP53(tumor protein p53 (LiFraumeni syndrome)) on chromosome 17p13.1 (19.2 Kb)}

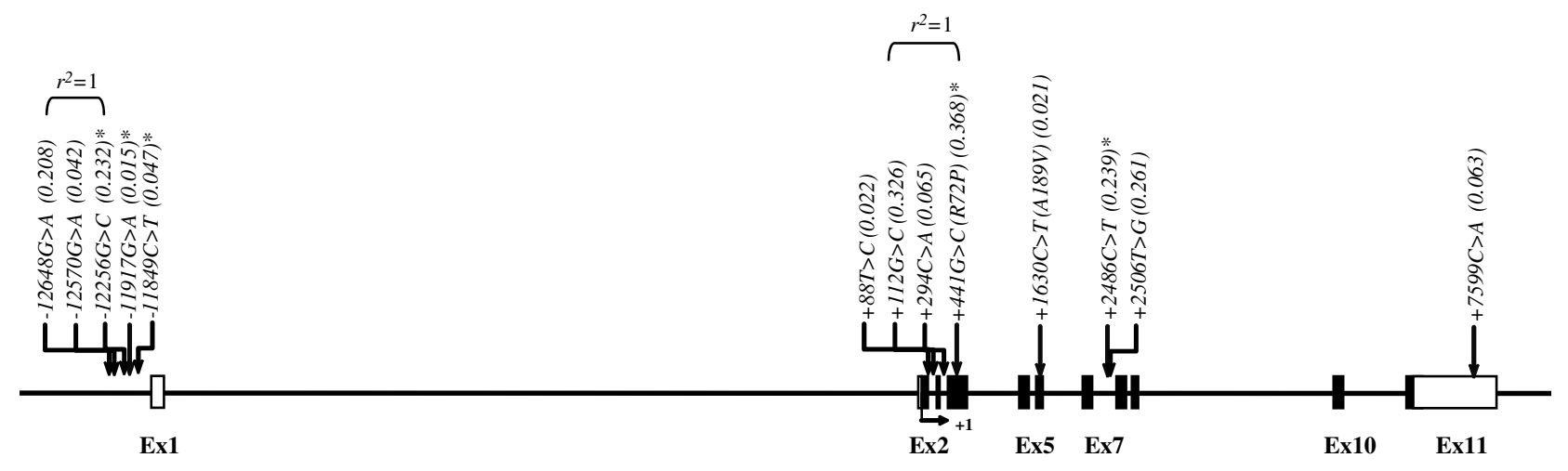

\section{B. Haplotype of TP53}

\begin{tabular}{|c|c|c|c|c|c|c|}
\hline Hap. & 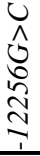 & 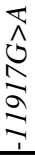 & 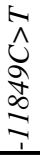 & \begin{tabular}{l}
$u$ \\
$\hat{N}$ \\
\multirow{7}{7}{} \\
+ \\
+
\end{tabular} & 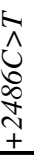 & Freq. \\
\hline$h t 1$ & $\bar{G}$ & $\bar{G}$ & $\bar{C}$ & $G$ & $\bar{C}$ & 0.620 \\
\hline$h t 2$ & $\mathrm{C}$ & G & $\mathrm{C}$ & $\mathrm{C}$ & $\mathrm{T}$ & 0.162 \\
\hline$h t 3$ & $\mathrm{G}$ & $\mathrm{G}$ & $\mathrm{C}$ & $\mathrm{C}$ & $\mathrm{C}$ & 0.098 \\
\hline Others. & & & & 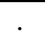 & & 0.120 \\
\hline
\end{tabular}

Fig. 1 Gene map, haplotypes, and linkage disequilibrium (LD) coefficients in TP53. a Gene map and single nucleotide polymorphisms (SNPs) in TP53 on chromosome 17p13.1 (reference sequence of TP53: OMIM No. 191170). Coding exons are marked by black blocks and $5^{\prime}$ and $3^{\prime}$ untranslated regions (UTR) by white blocks. Asterisks indicate SNPs that were genotyped in a larger population. The frequencies of SNPs without larger-scale genotyping were based

stratified analyses by age, gender, and smoking status as well as analyses of historical types of lung cancer, no significant associations were found between TP53 polymorphisms and lung cancer risk in a Korean population (Table 4).

\section{Discussion}

Based on the supposition that TP53 polymorphisms are associated with lung cancer risk and that these polymorphisms may play a role as a predictor of lung cancer development, we conducted a preliminary study on TP53 polymorphisms by sequencing at 24 samples and, for a further larger-scale study, selected five TP53 polymorphisms via genotyping in a total of 595 samples, consisting of 299 lung patients and 296 controls. Our findings indicated no significant association between polymorphisms of the TP53 gene and lung cancer risk in a Korean population.

\section{LDs among TP53 polymorphisms}

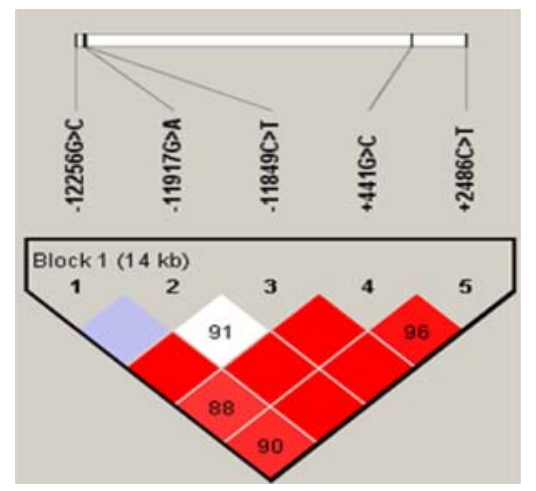

on sequencing data $(n=24)$. The first base of the translation site was denoted as nucleotide +1 . b Haplotypes of TP53. Haplotypes with frequency $>0.03$ are presented. c LD coefficient $\left(\left|D^{\prime}\right|\right)$ among TP53 SNPs. All five SNPs, $-12256 G>C,-11917 G>A,-11849 C>T$, $+441 G>C$, and $+2486 C>T$, were used for haplotype construction. Others included CGTCT, GGCCT, CGCGC, GACCT, GGCGT, and CGCGT

Considering the absence of association and the limitation of our study, the small number of study subjects might have affected the lack of association.

The tumor suppressor gene TP53 encodes a transcription factor that is activated in response to antiproliferative functions such as cell-cycle arrest and apoptosis (Kastan et al. 1995). Inactivation of TP53 by genetic alteration occurs frequently in a wide range of cancers (Soussi 2007). In particular, many groups have reported that the Arg72 and Pro72 variants of TP53 (Arg72Pro) showed ethnic and functional differences (Petitjean et al. 2007). Furthermore, numerous studies analyzed the impact of these polymorphisms on cancer risk, but these findings have been inconsistent. Popanda et al. (2007) and Zhang et al. (2006) reported that TP53 Arg72Pro polymorphism was significantly associated with susceptibility to lung cancer. In 2007, Mechanic et al. suggested that association with genetic variation in TP53 and lung cancer risk was different depending on race (Mechanic et al. 2007). On the 


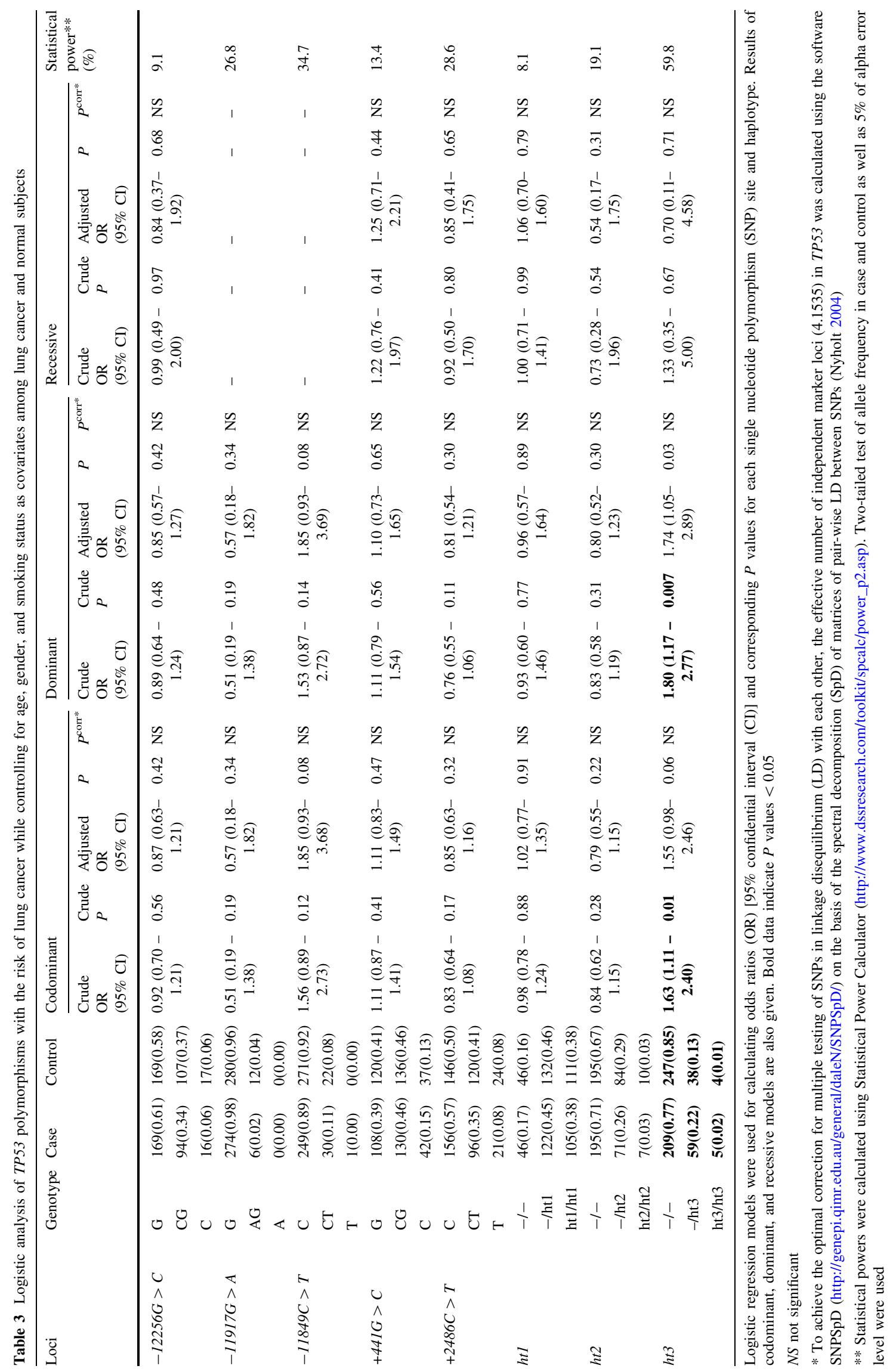




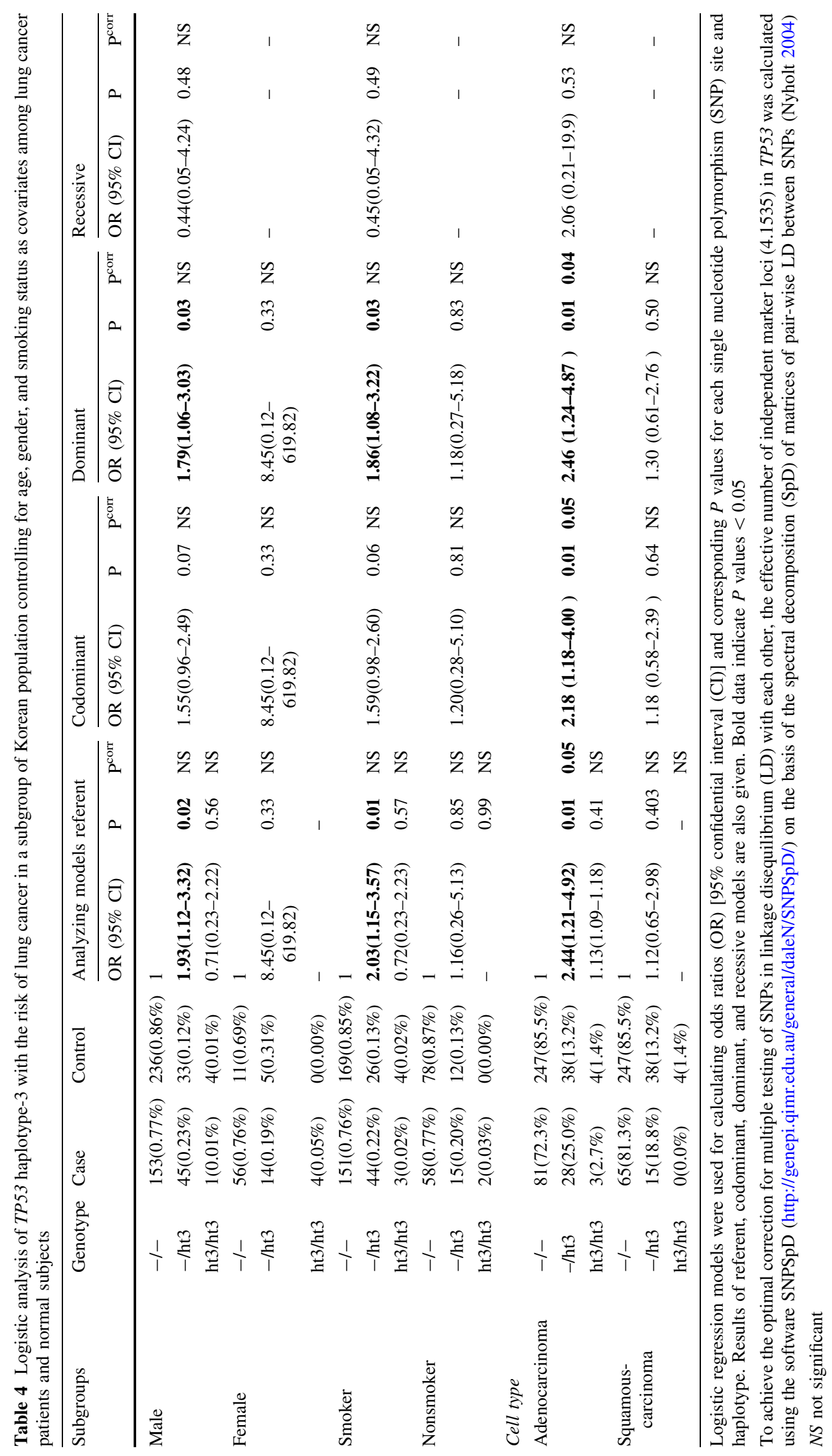


other hand, others could not find such association (Jin et al. 1995; Matakidou et al. 2003): Pierce et al. reported no significant association between the TP53 codon 72 polymorphisms and lung cancer (Pierce et al. 2000), and de las Penas et al. (2006) also suggested no association between TP53 polymorphisms and survival of patients with chemotherapy-treated non-small-cell lung cancer. Our data revealed that haplotype $3(-12256 \mathrm{G},-11917 \mathrm{G},-11849 \mathrm{C}$, +441C, +2486C) of TP53 showed marginal association with the lung cancer risk in overall, male gender, smokers, and adenocarcinoma cell types, but the association was lost after correction using SNPSpD. Therefore, our data was consistent with these studies, demonstrating no significant association with TP53 Arg72Pro and risk of lung cancer. In summary, 13 sequence variants of TP53 were identified in 24 Korean individuals through direct sequencing. We selected five of these polymorphisms for larger-scale genotyping $(n=595)$ and observed no significant difference in allele genotype distribution between lung cancer patients and controls. Thus, we concluded that no significant association exists between these TP53 polymorphisms, including TP53 Arg72Pro, and lung cancer risk in a Korean population.

\section{References}

de las Penas R, Sanchez-Ronco M, Alberola V, Taron M, Camps C, Garcia-Carbonero R, Massuti B, Queralt C, Botia M, GarciaGomez R, others (2006) Polymorphisms in DNA repair genes modulate survival in cisplatin/gemcitabine-treated non-smallcell lung cancer patients. Ann Oncol 17(4):668-675

Fuster JJ, Sanz-Gonzalez SM, Moll UM, Andres V (2007) Classic and novel roles of p53: prospects for anticancer therapy. Trends Mol Med 13(5):192-199

Hainaut P, Hollstein M (2000) p53 and human cancer: the first ten thousand mutations. Adv Cancer Res 77:81-137

Hazelton WD, Clements MS, Moolgavkar SH (2005) Multistage carcinogenesis and lung cancer mortality in three cohorts. Cancer Epidemiol Biomarkers Prev 14(5):1171-1181

Hedrick PW (1987) Gametic disequilibrium measures: proceed with caution. Genetics 117(2):331-341

Hollstein M, Sidransky D, Vogelstein B, Harris CC (1991) p53 mutations in human cancers. Science 253(5015):49-53

Jin X, Wu X, Roth JA, Amos CI, King TM, Branch C, Honn SE, Spitz MR (1995) Higher lung cancer risk for younger AfricanAmericans with the Pro/Pro p53 genotype. Carcinogenesis 16(9):2205-2008

Kastan MB, Canman CE, Leonard CJ (1995) P53, cell cycle control and apoptosis: implications for cancer. Cancer Metastasis Rev 14(1):3-15

Khadang B, Fattahi MJ, Talei A, Dehaghani AS, Ghaderi A (2007) Polymorphism of TP53 codon 72 showed no association with breast cancer in Iranian women. Cancer Genet Cytogenet 173(1):38-42

Matakidou A, Eisen T, Houlston RS (2003) TP53 polymorphisms and lung cancer risk: a systematic review and meta-analysis. Mutagenesis 18(4):377-385
Mechanic LE, Bowman ED, Welsh JA, Khan MA, Hagiwara N, Enewold L, Shields PG, Burdette L, Chanock S, Harris CC (2007) Common genetic variation in TP53 is associated with lung cancer risk and prognosis in African Americans and somatic mutations in lung tumors. Cancer Epidemiol Biomarkers Prev 16(2):214-222

Nadji SA, Mahmoodi M, Ziaee AA, Naghshvar F, Torabizadeh J, Yahyapour Y, Nategh R, Mokhtari-Azad T (2007) An increased lung cancer risk associated with codon 72 polymorphism in the TP53 gene and human papillomavirus infection in Mazandaran province, Iran. Lung Cancer 56(2):145-151

Nyholt DR (2004) A simple correction for multiple testing for singlenucleotide polymorphisms in linkage disequilibrium with each other. Am J Hum Genet 74(4):765-769

Petitjean A, Achatz MI, Borresen-Dale AL, Hainaut P, Olivier M (2007) TP53 mutations in human cancers: functional selection and impact on cancer prognosis and outcomes. Oncogene 26(15):2157-2165

Pierce LM, Sivaraman L, Chang W, Lum A, Donlon T, Seifried A, Wilkens LR, Lau AF, Le Marchand L (2000) Relationships of TP53 codon 72 and HRAS1 polymorphisms with lung cancer risk in an ethnically diverse population. Cancer Epidemiol Biomarkers Prev 9(11):1199-1204

Popanda O, Edler L, Waas P, Schattenberg T, Butkiewicz D, Muley T, Dienemann H, Risch A, Bartsch H, Schmezer P (2007) Elevated risk of squamous-cell carcinoma of the lung in heavy smokers carrying the variant alleles of the TP53 Arg72Pro and p21 Ser31Arg polymorphisms. Lung Cancer 55(1):25-34

Rajaraman P, Wang SS, Rothman N, Brown MM, Black PM, Fine HA, Loeffler JS, Selker RG, Shapiro WR, Chanock SJ, others (2007) Polymorphisms in apoptosis and cell cycle control genes and risk of brain tumors in adults. Cancer Epidemiol Biomarkers Prev 16(8):1655-1661

Sanchez-Cespedes M (2003) Dissecting the genetic alterations involved in lung carcinogenesis. Lung Cancer 40(2):111-121

Shin HR, Won JY, Jung KW, Kong KW, Yim SH, Lee JK, Noh HI, Lee JK, Pisani P, Park JG (2005) Nationwide cancer incidence in Korea, 1999-2001; first result using the national cancer incidence database. Cancer Res Treatment 37(6):325-331

Soussi T (2007) p53 alterations in human cancer: more questions than answers. Oncogene 26(15):2145-2156

Sozzi G, Pastorino U, Moiraghi L, Tagliabue E, Pezzella F, Ghirelli C, Tornielli S, Sard L, Huebner K, Pierotti MA, others (1998) Loss of FHIT function in lung cancer and preinvasive bronchial lesions. Cancer Res 58(22):5032-5037

Stephens M, Smith NJ, Donnelly P (2001) A new statistical method for haplotype reconstruction from population data. Am J Hum Genet 68(4):978-989

Toloza EM, Morse MA, Lyerly HK (2006) Gene therapy for lung cancer. J Cell Biochem 99(1):1-22

Wistuba II, Gazdar AF, Minna JD (2001) Molecular genetics of small cell lung carcinoma. Semin Oncol 28(2 Suppl 4):3-13

Yokomizo A, Tindall DJ, Drabkin H, Gemmill R, Franklin W, Yang P, Sugio K, Smith DI, Liu W (1998) PTEN/MMAC1 mutations identified in small cell, but not in non-small cell lung cancers. Oncogene 17(4):475-479

Zambetti GP (2007) The p53 mutation "gradient effect" and its clinical implications. J Cell Physiol 213(2):370-373

Zhang X, Miao X, Guo Y, Tan W, Zhou Y, Sun T, Wang Y, Lin D (2006) Genetic polymorphisms in cell cycle regulatory genes MDM2 and TP53 are associated with susceptibility to lung cancer. Hum Mutat 27(1):110-117 